\title{
A reminder of extinction reduces relapse in an animal model of voluntary behavior
}

\author{
Javier Nieto, ${ }^{1}$ Metin Uengoer, ${ }^{2}$ and Rodolfo Bernal-Gamboa ${ }^{1}$ \\ ${ }^{1}$ Facultad de Psicología, División de Investigación y Estudios de Posgrado, Universidad Nacional Autónoma de México, Coyoacán, \\ 04510 Ciudad de México, Mexico; ${ }^{2}$ Philipps-Universität Marburg, Marburg 35037, Germany
}

\begin{abstract}
One experiment with rats explored whether an extinction-cue prevents the recovery of extinguished lever-pressing responses. Initially, rats were trained to perform one instrumental response (R1) for food in Context $A$, and a different instrumental response (R2) in Context B. Then, responses were extinguished each in the alternate context (R1 in Context B; R2 in Context A). For one group, extinction of both responses was conducted in the presence of an extinction-cue, whereas in a second group, the extinction-cue only accompanied extinction of R1. During a final test, we observed that returning the rats to the initial acquisition context renewed performance and that response recovery was attenuated in the presence of the cue that accompanied extinction of the response. The impact of the extinction-cue, however, was not transferred to the response that has been extinguished without the cue. Our results are consistent with the idea that extinction established an inhibitory cueresponse association.
\end{abstract}

In parallel to Pavlovian extinction (e.g., Bouton and Woods 2008), recent research on instrumental extinction documented that the behavioral decline induced by reinforcer omission is rather context-dependent. For instance, Nakajima et al. (2000) trained rats to press a lever for food in Context $\mathrm{A}$, followed by extinction of the response in a second Context B. Nakajima et al. (2000) found that returning subjects to the original context (Context A) during testing resulted in a recovery of lever-pressing behavior (i.e., ABA renewal). Moreover, renewal of instrumental behavior was also observed when acquisition, extinction, and test took place in three different contexts (i. e., ABC renewal, Todd 2013) or when acquisition and extinction were conducted in the same context, but testing occurred in a second one (i.e., AAB renewal; Bouton et al. 2011; Todd et al. 2012).

The evidence of $\mathrm{ABA}, \mathrm{AAB}$, and $\mathrm{ABC}$ renewal of instrumental behavior has rather troubling implications for behavior therapy. These phenomena indicate that even after a successful clinical intervention that eliminated an unwanted voluntary behavior, the probability of relapse (renewal) increases as the patient leaves the therapeutic setting (extinction context). Thus, the evaluation of experimental strategies that attenuate or prevent the recovery of extinguished instrumental behaviors might be beneficial for improving the long-term success of therapeutic interventions. One of these strategies involves the application of reminder cues. For instance, Willcocks and McNally (2014) reported a reduction in ABA renewal of alcohol seeking in rats when testing was conducted in the presence of a stimulus associated with extinction. In their experiment, animals were initially trained to nose poke for alcoholic beer in Context A. Then, extinction was conducted in Context B. Throughout those sessions, a 60-sec tone (extinction-cue) was presented at regular intervals noncontingent on the animal's behavior. During a final test phase conducted in Context A, Willcocks and McNally observed that the presence of an extinction-cue reduced response recovery compared with a condition for which testing took place in the absence of the tone-stimulus.

Willcocks and McNally's (2014) findings suggest that an extinction-cue is able in some way to inhibit instrumental re-

\section{Corresponding author: rbernalg@unam.mx}

Article is online at http://www.learnmem.org/cgi/doi/10.1101/Im.044495.116. sponding, but their experiment was not designed to specify the nature of this inhibition. The aim of the present experiment was to investigate the mechanisms underlying the impact of extinction-cues on response recovery. According to one approach, an extinction-cue may act through a direct inhibitory association with the representation of the reinforcer (Rescorla and Wagner 1972). A second possibility proposes that an extinction-cue operates by regulating retrieval of entire response-reinforcer associations akin to a negative occasion setter (Bouton 1997). According to a third possibility, an extinction-cue modulates behavior by directly inhibiting a specific response (Rescorla 1993).

Each of these three accounts is able to explain attenuation of response recovery induced by an extinction-cue. However, they differ in their predictions whether the behavioral impact of an extinction-cue transfers to other responses that were extinguished in the absence of the cue. According to the first account, the effectiveness of an extinction-cue should transfer completely to other responses having a learning history with the same outcome. The occasion-setting account also gives reason to expect that the impact of extinction-cues should transfer to other extinguished responses. However, in contrast to the first possibility, research on occasion-setting documented that the transfer of occasion-setters is generally incomplete (e.g., Schmajuk and Holland 1998; c.f., Holland 1991). According to the third account, the behavioral impact of an extinction-cue should be restricted to the response with which it was trained, and no transfer at all to other responses should occur. The purpose of the present experiment was to differentiate between the three accounts.

The design of the present experiment is shown in Table 1. To control associative values of responses and contexts, we equated histories of reinforcement and nonreinforcement using a procedure similar to Todd (2013). Initially, all rats were trained to perform one instrumental response (R1; pressing the left or the right lever) for food in Context $\mathrm{A}$, and a second response (R2;

\footnotetext{
(C) 2017 Nieto et al. This article is distributed exclusively by Cold Spring Harbor Laboratory Press for the first 12 months after the full-issue publication date (see http://learnmem.cshlp.org/site/misc/terms.xhtml). After 12 months, it is available under a Creative Commons License (AttributionNonCommercial 4.0 International), as described at http://creativecommons. org/licenses/by-nc/4.0/.
} 
Table 1. Experimental design

\begin{tabular}{lllll}
\hline & & & \multicolumn{2}{c}{ Test } \\
\cline { 4 - 5 } Group & Acquisition & Extinction & \multicolumn{1}{c}{$\begin{array}{c}\text { Extinction } \\
\text { condition }\end{array}$} & \multicolumn{1}{c}{$\begin{array}{c}\text { Renewal } \\
\text { condition }\end{array}$} \\
\hline EC & A: R1-O & B: X.R1- & B: X.R1- & A: X.R1- \\
NEC & B: R2-O & A: X.R2- & A: X.R2- & B: R2- \\
& A: R1-O & B: X.R1- & B: X.R1- & A: X.R1- \\
& B: R2-O & A: R2- & A: R2- & B: X.R2- \\
\hline
\end{tabular}

Rats in Group EC received presentations of a tone for both responses during extinction. For Group NEC only one response underwent extinction in the presence of the tone. R1 and R2 refer to pressing the left or the right lever counterbalanced. "R1-O" and "R2-O" means that pressing the lever was reinforced. "R1-" and "R2-" means that pressing the lever was not reinforced. " $\mathrm{X}$ " means that rats received brief presentations of a tone during the session.

pressing the left or the right lever) for food in Context B. Then, R1 was extinguished in Context B, while R2 underwent extinction in Context A. Finally, each response was tested for response recovery in its original acquisition context (R1 in Context A; R2 in Context B). For half of the animals (Group EC), extinction of both responses was conducted in the presence of a tone-stimulus, Cue $\mathrm{X}$ (extinction-cue), whereas during the subsequent test in the acquisition context (renewal context), Cue X was only presented for R1. For the other half (Group NEC), Cue X only accompanied extinction of R1, but was presented for either response during the test in the acquisition context. If Cue $\mathrm{X}$ is effective in reducing response recovery during the test stage, animals in Group EC should show lower levels of performing R1 in Context A compared with R2 in Context B. And, if the behavioral impact of Cue X completely transfers to other responses, animals in Group NEC should show similar levels of performing $\mathrm{R} 1$ and $\mathrm{R} 2$ in Context $\mathrm{A}$ and Context B, respectively. If there is transfer of Cue X's power, but only partial, we should observe weaker response recovery for R2 in Group NEC than in Group EC. In contrast, according to the inhibitory cue-response account, response recovery in R2 should be independent of the presence (Group NEC) or absence (Group EC) of Cue X (see Fig. 1).

Thirty-two female 3-mo-old experimentally naïve Wistar rats weighting in average $260.3 \mathrm{~g}$ were used. They were individually housed in methracrylate cages $(21 \times 24 \times 46 \mathrm{~cm}, H \times W \times D)$ inside a room maintained on a $12-12 \mathrm{~h}$ light-dark cycle. All subjects were maintained with ad libitum access to water but were food-deprived to $83 \%$ of their initial body weights throughout the experiment.

Eight identical chambers manufactured by MED Associates (model ENV-008) measuring $29 \times 22 \times 24 \mathrm{~cm}$, $(H \times W \times D)$ were used. Each chamber was enclosed in a sound attenuating chamber. The side walls and ceiling were made of clear acrylic plastic, while the front and rear walls were made of stainless steel. The floor of the chamber consisted of sixteen $0.5-\mathrm{cm}$ diameter stainless steel rods spaced $1.5 \mathrm{~cm}$ apart. A recessed $5 \mathrm{~cm} \times 5 \mathrm{~cm}$ food magazine in which $45 \mathrm{mg}$ Noyes A/I pellets could be delivered was centered on the front wall. Each chamber had two retractable levers, they were positioned to the right and to the left of the food tray. These levers were $4.8 \mathrm{~cm}$ long and positioned $6.8 \mathrm{~cm}$ above the floor. A $28 \mathrm{Vdc}$ bulb was placed $4.2 \mathrm{~cm}$ above the lever which served as a general house light. A $3000 \mathrm{~Hz}$ tone, (80 dB) delivered through a $8.2 \mathrm{~cm}$ speaker mounted to the ceiling of the sound attenuation chamber was used as an extinction-cue. The chambers were connected to a PC that controlled and recorded the events.

The chambers were set up to provide two different sets of contextual cues. Four chambers provided one context consisted of vinegar scent provided with a dish containing $5 \mathrm{~mL}$ of white vinegar placed outside each chamber near the front wall. The floor consisted of sixteen $0.5 \mathrm{~cm}$ diameter stainless steel rods spaced $1.5 \mathrm{~cm}$ apart. Four additional chambers provided another context where a sandpaper sheet covered the floor, and odor was provided by $5 \mathrm{~mL}$ of Windex placed outside each chamber. Scents were refreshed daily. Contexts were counterbalanced as A and B across rats.

Sessions were conducted on successive days at the same time each day. Prior to acquisition, half of the rats were first exposed to Context A, and then Context B. For the other half the opposite was true. Sessions were separated by $1 \mathrm{~h}$. During those sessions food pellets were delivered approximately 65 times at a variable time (VT) 30-sec schedule. No levers were presented. Each session lasted $30 \mathrm{~min}$.

Acquisition. For $6 \mathrm{~d}$, rats were trained in two daily sessions to press two levers for food on a variable interval (VI) 30-sec schedule. Only one lever was available in a particular context. Contexts and responses were fully counterbalanced. R1 was trained in Context A, while R2 in Context B. Sessions were separated by $3 \mathrm{~h}$. Each session lasted $30 \mathrm{~min}$.

Extinction. Rats received two daily extinction sessions for 4 d. R1 was extinguished in Context B, while R2 was extinguished in Context A. In each of the extinction sessions, rats in Group EC received approximately 65 presentations of a 5-sec tone which was produced by a VT $30 \mathrm{sec}$ (extinction-cue). The tone was presented for the extinction of both responses. Rats in Group NEC, only receieved the presentations of the tone during extinction of R1. Sessions were separated by $3 \mathrm{~h}$. Each session lasted $30 \mathrm{~min}$.

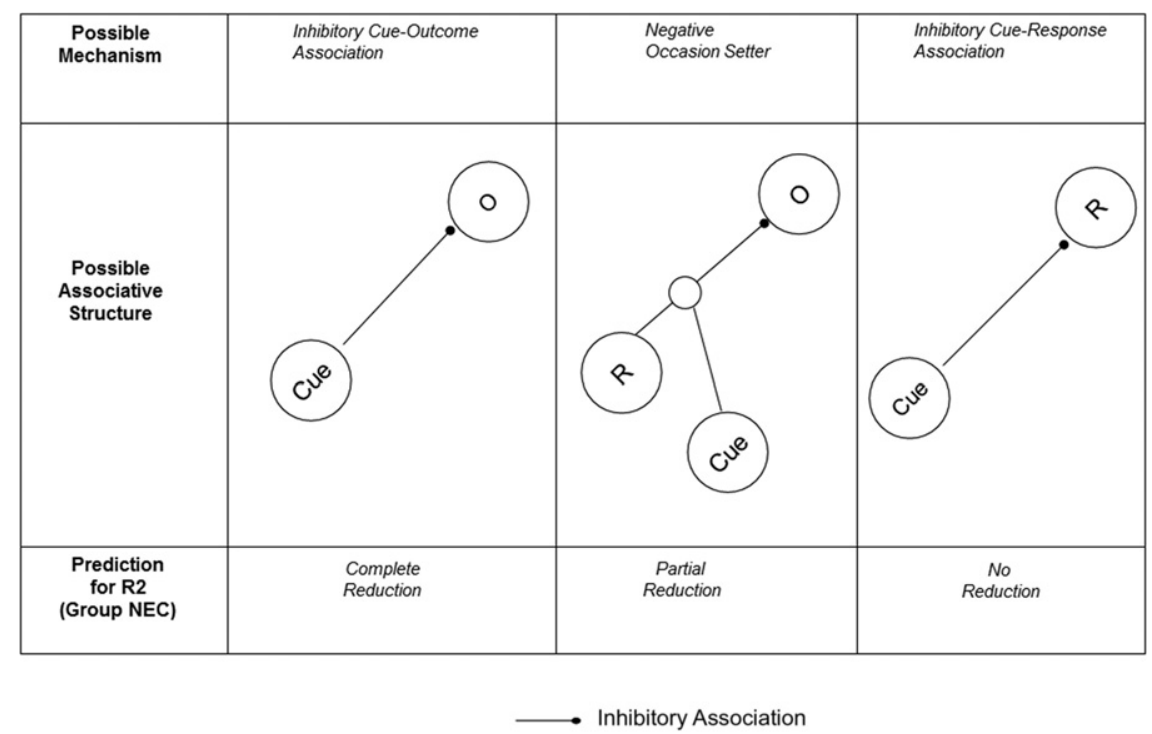

Figure 1. Possible associative structures and predictions according to the three different accounts. Cue, R, and O stands for extinction-cue, response, and outcome, respectively. 
Test. Rats received a single 10 min test session for both responses in both the extinction and renewal contexts. Each session was separated by $60 \mathrm{~min}$. There was only one lever available during each session of test and no reinforcers were delivered. The order of testing responses and contexts was fully counterbalanced across rats. For Group EC, R1 was tested in the presence of the extinction-cue in both contexts, whereas R2 was tested with the extinction-cue only in the extinction context. Rats in Group NEC received testing of $\mathrm{R} 1$ in the presence of the extinction-cue in both contexts, while testing of R2 occurred with the extinctioncue only in the renewal context.

Mean responses per minute were compared using analyses of variance (ANOVA). The rejection criterion was set at $P=0.05$, and effect sizes were reported using partial eta-squared $\left(\eta_{p}^{2}\right)$.

Figure 2 shows the mean responses per minute during the six sessions of acquisition (left panel) and the four sessions of extinction (right panel).

A 2 (Group) $\times 2$ (Response) $\times 6$ (Session) ANOVA conducted with the acquisition data confirmed that both responses were acquired similarly by all rats and that responding increased as acquisition progressed. The analysis found a significant main effect of session, $F_{(5,300)}=197.32$, mean square error $(\mathrm{MSe})=15.4, P=$ $0.001, \eta_{p}^{2}=0.76$, and, unexpectedly, a Group $\times$ Session interaction, $F_{(5,300)}=2.46$, MSe $=15.4, P=0.03, \eta_{p}^{2}=0.03$. Most important, the main effect of response and all related interactions including this factor did not reach significance, all $F s<1$, showing that there was no difference in acquisition between $\mathrm{R} 1$ and R2. The main effect of group was also not significant, $F_{(1,60)}=$ 1.61. $\mathrm{MSe}=202.9, P=0.20$.

An exploration of the Group $\times$ Session interaction revealed that rats in Group EC showed higher levels of lever pressing only in Session $5, F_{(1,60)}=4.01$, MSe, $=63.09, P=0.04$.

A 2 (Group) $\times 2$ (Response) $\times 4$ (Session) ANOVA conducted with the data of extinction found a significant main effect of session, $F_{(3,180)}=157.97$, MSe $=1.68, P=0.001, \eta_{p}^{2}=0.72$. Most important, the main effect of response and all related interactions including this factor did not reach significance, largest $F_{(3,180)}=$

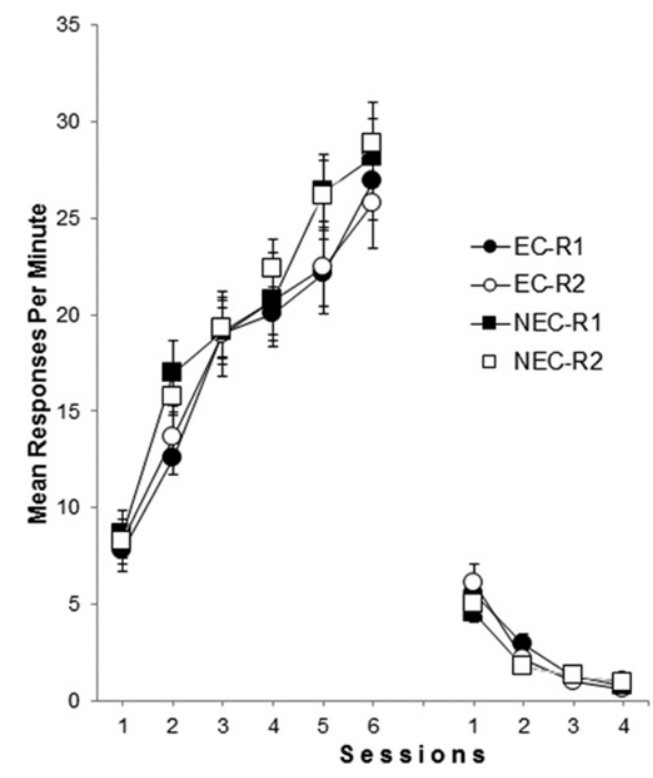

Figure 2. The left diagram shows mean responding during each session of acquisition for the two responses R1 and R2 in Groups EC and NEC, while the right diagram shows mean responding during each session of extinction for both responses in the two groups. Error bars denote standard errors of the mean.
$1.25, \mathrm{MSe}=1.68, P=0.29$, indicating that extinction proceeded similarly for R1 and R2. The main effect of group was also not significant, $F_{(1,60)}=1.52$, MSe $=6.18, P=0.22$, but we found an unexpected Group $\times$ Session interaction, $F_{(3,180)}=3.62, \mathrm{MSe}=$ 1.68, $P=0.01, \eta_{p}^{2}=0.05$. However, subsequent analyses on the level of individual sessions showed no differences between groups, largest $F_{(1,60)}=2.76, \mathrm{MSe}=6.60, P=0.10$.

Figure 3 shows the mean responses per minute for R1 and R2 in both the extinction and renewal contexts during testing. A 2 $($ Group) $\times 2$ (Response) $\times 2$ (Context) ANOVA conducted with the test data found a significant main effect of context, $F_{(1,60)}=$ 158.38 , MSe $=10.36, P=0.001, \eta_{p}^{2}=0.72$, confirming that responding was higher in the renewal context compared with the extinction context. The analysis also revealed a significant main effect of response, $F_{(1,60)}=7.74, \quad$ MSe $=11.50, \quad P=0.007$ $\eta_{p}^{2}=0.11$, and a Response $\times$ Context interaction $F_{(1,60)}=12.73$, MSe $=10.36, P=0.01, \eta_{p}^{2}=0.17$, showing that the strength of response recovery was higher for R2 than R1. However, the difference in context-dependency between R1 and R2 was equal across the two groups as indicated by the absence of a Group $\times$ Response $\times$ Context interaction, $F<1$. The main effect of group and the remaining two-way interactions including this factor were also not significant, all $F \mathrm{~s}<1$.

Planned comparisons confirmed for each group that responding in the renewal context was stronger for R2 than for R1, Group EC: $t_{(60)}=5.96, P=0.01$; Group NEC: $t_{(60)}=4.28$, $P=0.04$. And, the response level of $\mathrm{R} 2$ in the renewal context did not differ between the groups, $t_{(60)}=0.006, P=0.93$.

One experiment with rats investigated the effects of an extinction-cue on renewal of voluntary responses. Response recovery of an extinguished instrumental response was attenuated when testing was conducted in the presence of an extinction-cue that accompanied extinction of the response. In addition, we found that response recovery was independent of the presence or absence of a cue that accompanied extinction of another response.

The impact of extinction-cues on instrumental behavior has previously been demonstrated by Willcocks and McNally (2014) for alcohol seeking in rats. The present study extends their finding to instrumental learning with food reinforcers. Moreover, our results extend the generality of other reports that documented the effectiveness of extinction-cues in different fields of Pavlovian conditioning, including appetitive Pavlovian conditioning in rats (Brooks and Bouton 1994), human fear conditioning (Dibbets et al. 2008), exposure treatments with social drinkers (Collins and Brandon 2002), and with arachnophobic patients (Mystkowski et al. 2006).

Our finding that an extinction-cue did not transfer its modulatory impact to other responses is inconsistent with the idea that extinction-cues act by inhibitory cue-outcome associations (Rescorla and Wagner 1972). In the present experiment, both of the two responses were trained with the same food reinforcer. Therefore, an extinction-cue that directly inhibits the representation of the outcome should have influenced the performances of both responses in the same way. The absence of transfer is also challenging the idea that extinction-cues influence behavior by regulating the retrieval of response-reinforcer connections akin to occasion setters (Bouton 1997). Research on occasion setting revealed ample evidence that the behavioral impact of negative occasion setters transfers across suitable targets (e.g., Holland and Coldwell 1993; Todd 2013). In the present study, both responses shared a history of extinction. Even though one of the responses underwent extinction in the absence of the extinction-cue, the history of extinction should have made this response a suitable target for the modulatory impact of the extinction-cue. In contrast, the inhibitory cue-response account (Rescorla 1993; Todd 


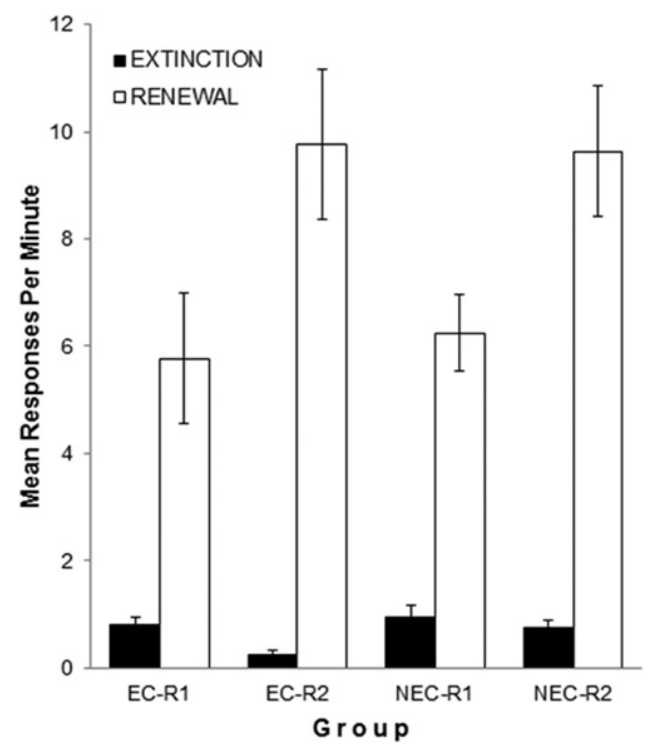

Figure 3. Mean responding of R1 and R2 during the test sessions in the extinction and renewal contexts for both groups. Error bars denote standard errors of the mean.

2013; Todd et al. 2014) predicts that the behavioral impact of an extinction-cue should be restricted to the response with which it was trained. The present results are in full agreement with this latter approach.

One way to reconcile the inhibitory cue-outcome account with the present results would be by assuming that inhibition of the outcome representation is not controlled by a representation encoding solely the extinction-cue, but rather by a configural representation (e.g., Whitlow and Wagner 1972; Pearce 1994) comprising the extinction-cue together with the context of extinction. According to the configural approach, the presence and absence of an extinction-cue modulate behavior by changing the similarity between the conditions of extinction and testing. Willcocks and McNally (2014, Experiment 2) reported results that were inconsistent with this analysis by showing that ABA renewal of instrumental responding was not reduced when testing took place in the presence of a neutral cue lacking any prior involvement in extinction treatment. However, the authors did not compare directly the impacts of an extinction-cue and a neutral cue on response recovery, which may be investigated in future research in order to further differentiate between the configural approach and the inhibitory cue-response account.

In the present experiment, a response that was extinguished in the absence of an extinction-cue served as the target for assessing the transfer of behavioral control by an extinction-cue. Pavlovian experiments documented that the mere history of extinction can make a stimulus a suitable target for transfer exerted by the feature of an occasion setting procedure (Rescorla 1985; Swartzentruber and Rescorla 1994, see also Bouton 1991). However, according to Holland (1983, 1985), a stimulus becomes a suitable target for transfer only when responding to that stimulus was previously modulated by another occasion setting feature. In light of this, future research is required to investigate whether an extinction-cue transfers its behavioral control to responses that were extinguished in the presence of other extinction-cues.

In the present study, treatment of the extinction-cue was not matched in all respects across the two experimental groups. For instance, animals in Group EC received a higher number of extinction-cue presentations during the extinction phase than those in Group NEC. The number of extinction-cue presentations was also not matched across groups for testing in the renewal context. Procedural group differences as those might cause differences in processing of the extinction-cue in terms of habituation or sensitization. In the present study, there is no evidence for such group differences in nonassociative processing of the extinction cue as, for instance, performance of R1 in the renewal context was equal between groups, $t_{(60)}=0.08, P=0.77$. Nevertheless, it will be necessary to demonstrate the generality of the present findings in future research that controls for aspects of habituation/sensitization. Furthermore, both of the present groups differed in the number of responses related to the extinction-cue (two responses in Group EC; one response in Group NEC). It is possible that the number of related responses influences a cue's capability to transfer its modulatory impact to another response. Future research will be required to investigate possible factors determining modulatory transfer of extinction-cues.

Besides their theoretical implications, our findings are promising to therapists, because they strongly suggest that the use of extinction-cue strategies in clinical settings could be effective in thwarting relapse of voluntary unhealthy behaviors such as drug abuse and self-injury. However, the present results also indicate some important restrictions, because they imply that the patient would learn to inhibit a specific problematic behavior only under specific cues which would weaken the degree of transfer of such treatments.

\section{Acknowledgments}

This research was funded by UNAM-DGAPA through grant project PAPIIT IN306015 and IA302916.

\section{References}

Bouton ME. 1991. Context and retrieval in extinction and in other examples of interference in simple associative learning. In Current topics in animal learning: brain, emotion and cognition (ed. Dachowski LW, Flaherty CF), pp. 25-53. Erlbaum, Hillsdale, NJ.

Bouton ME. 1997. Signals for whether versus when an event will occur. In Learning, motivation and cognition: the functional behaviourism of Robert C. Bolles (ed. Bouton ME, Fanselow MS), pp. 358-409. American Psychological Association, Washington, DC.

Bouton ME, Woods AM. 2008. Extinction: behavioral mechanisms and their implications. In Learning and memory: a comprehensive reference (ed. Byrne JH, Sweatt D, Menzel R, Eichenbaum $\mathrm{H}$, Roediger H), Vol. 1, Learning theory and behaviour, pp. 151-171. Elsevier, Oxford.

Bouton ME, Todd TP, Vurbic D, Winterbauer N. 2011. Renewal after the extinction of free operant behavior. Learn Behav 39: 57-67.

Brooks DC, Bouton ME. 1994. A retrieval cue for extinction attenuates response recovery (renewal) caused by a return to the conditioning context. J Exp Psychol Anim Behav Process 20: 366-379.

Collins BN, Brandon TH. 2002. Effects of extinction context and retrieval cues on alcohol cue reactivity among nonalcoholic drinkers. J Consult Clin Psychol 70: 390-397.

Dibbets P, Havermans R, Arntz A. 2008. All we need is a cue to remember: the effect of an extinction cue on renewal. Behav Res Ther 46: 1070-1077.

Holland PC. 1983. Occasion Setting in Pavlovian feature positive discriminations. In Quantitative analyses of behavior: discrimination processes (ed. Commons ML, Herrnstein RJ, Wagner AR), pp. 183-206. Ballinger, New York.

Holland PC. 1985. The nature of conditioned inhibition in serial and simultaneous feature negative discriminations. In Information processing in animals: conditioned inhibition (ed. Miller RR, Spear NE), pp. 267-297. Erlbaum, Hillsdale, NJ.

Holland PC. 1991. Acquisition and transfer of occasion setting in operant feature positive and feature negative discriminations. Learn Motiv 22: 366-387.

Holland PC, Coldwell SE. 1993. Transfer of inhibitory stimulus control in operant feature-negative discrimination. Learn Motiv 24: 345-375. 
Mystkowski JL, Craske MG, Echiverri AM, Labus JS. 2006. Mental reinstatement of context and return of fear in spider-fearful participants. Behav Ther 37: 49-60.

Nakajima S, Tanaka S, Urushihara K, Imada H. 2000. Renewal of extinguished lever-press responses upon return to the training context. Learn Motiv 31: 416-431.

Pearce JM. 1994. Similarity and discrimination: a selective review and a connectionist model. Psychol Rev 101: 587-607.

Rescorla RA. 1985. Conditioned inhibition and facilitation. In Information processing in animals: conditioned inhibition (ed. Miller RR, Spear NE), pp. 299-326. Erlbaum, Hillsdale, NJ.

Rescorla RA. 1993. Inhibitory associations between S and R in extinction. Anim Learn Behav 21: 327-336.

Rescorla RA, Wagner AR. 1972. A theory of Pavlovian conditioning: variations in the effectiveness of reinforcement and non-reinforcement. In Classical conditioning II: current theory and research (ed. Black AH, Prokasy WF), pp. 64-99. Appleton-Century Crofts, New York, NY.

Schmajuk NA, Holland PC. 1998. Occasion setting, associative learning and cognition in animals. American Psychological Association, Washington, DC.
Swartzentruber D, Rescorla RA. 1994. Modulation of trained and extinguished stimuli by facilitators and inhibitors. Animal Learning and Behavior 22: 309-316.

Todd TP. 2013. Mechanisms of renewal after the extinction of instrumental behavior. J Exp Pscyhol Anim Behav Process 39: 193-207.

Todd TP, Winterbauer NE, Bouton ME. 2012. Contextual control of appetite: renewal of inhibited food-seeking behavior in sated rats after extinction. Appetite 58: 484-489.

Todd TP, Vurbic D, Bouton ME. 2014. Mechanism of renewal after the extinction of discriminated operant behavior. J Exp Psychol Anim Learn Cogn 40: 355-368.

Willcocks AL, McNally GP. 2014. An extinction retrieval cue attenuates renewal but not reacquisition of alcohol seeking. Behavioral Neuroscience 128: 83-91.

Whitlow JW Jr, Wagner AR. 1972. Negative patterning in classical conditioning: summation of response tendencies to isolable and configural components. Psychon Sci 27: 299-301.

Received October 22, 2016; accepted in revised form November 2, 2016. 


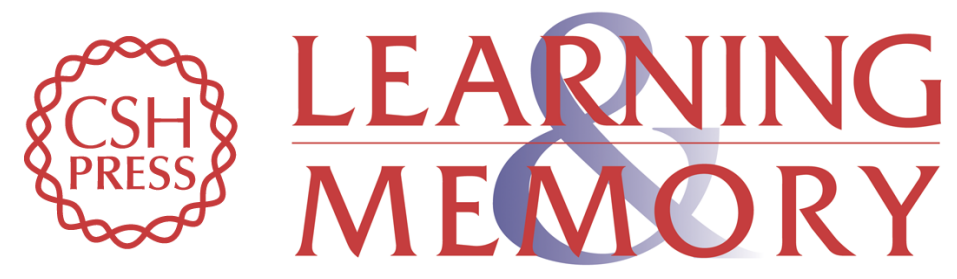

\section{A reminder of extinction reduces relapse in an animal model of voluntary behavior}

Javier Nieto, Metin Uengoer and Rodolfo Bernal-Gamboa

Learn. Mem. 2017, 24:

Access the most recent version at doi:10.1101/Im.044495.116

$\begin{aligned} & \begin{array}{r}\text { Creative } \\ \text { Commons } \\ \text { License }\end{array} \begin{array}{l}\text { This article is distributed exclusively by Cold Spring Harbor Laboratory Press for the } \\ \text { first } 12 \text { months after the full-issue publication date (see } \\ \text { http://learnmem.cshlp.org/site/misc/terms.xhtml). After } 12 \text { months, it is available under } \\ \text { a Creative Commons License (Attribution-NonCommercial } 4.0 \text { International), as } \\ \text { described at http://creativecommons.org/licenses/by-nc/4.0/. }\end{array} \\ & \begin{array}{c}\text { Receive free email alerts when new articles cite this article - sign up in the box at the } \\ \text { top right corner of the article or click here. }\end{array} \\ & \begin{array}{c}\text { Service } \\ \hline\end{array}\end{aligned}$

